\title{
Effects of $\mathrm{SiC}_{\mathrm{p}}$ Reinforcement on the Abrasive Wear Properties of Al-Si Alloy
}

\author{
Raj Kumar Singh ${ }^{\# 1}$, Mohammad Mohsin Khan ${ }^{\# 2}$, Amit Telang ${ }^{\# 3}$ \\ \# Department of Mechanical Enginerering, MANIT,Bhopal-462003, India \\ raju_tit@yahoo.co.in
}

\begin{abstract}
In the present investigation, an attempt has been made to analyze the high stress abrasive wear response of a SiC particle reinforced $\mathrm{Al}-\mathrm{Si}$ alloy. The wear test were conducted on a Pin on Disc machine at linear velocity of $1.26 \mathrm{~m} / \mathrm{s}$ the applied load range of 1-7 $\mathrm{N}$ while the abrasive platform used is 600 grit emery paper. To examine the influence of the $\mathrm{SiC}$ particle dispersion matrix alloy was also characterized under similar condition. The wear rate and coefficient of friction decreases with abrading distance while a reverse trend was observed. In case of frictional heating which gradually increases with the abrading distance. Incorporation of $\mathrm{SiC}$ improves the wear resistance of the matrix alloy and increasing the percentage of $\mathrm{SiC}$ increases the frictional heating and reduces the friction coefficient of the test material.
\end{abstract}

Keywords: AMMCs, SiC particulate, Stir Casting, Abrasive wear, Pin on disc machine, SEM.

\section{INTRODUCTION}

Aluminium alloys because of their ease of processing and light weight have wide range of applications such as aerospace, automobile and other engineering sectors. A combination of hard dispersoid is such as $\mathrm{Al}_{2} \mathrm{O}_{3}, \mathrm{SiC}$, $\mathrm{B}_{4} \mathrm{C}$ etc. in Al-alloys increases stiffness and strength but decrease ductility. The synthesis and characterization of aluminium matrix composites (AMCs) requires significant attention among MMCs and poor machinability is one of major disadvantage of AMCs [1-5]. Because of hard dispersoid causing great damage to the machining tools.

Various types of ceramic materials such as silicon carbide, zircon, alumina etc. have been used as dispersoid for synthesis composites [6-29] and few research has been made to natural minerals such as granite, corundum, sillimanite, etc. for making aluminium alloy \& its composite, though these natural minerals have numerous capacity for using as reinforcement [30-36]. Because of excellent higher stiffness as well as wear resistance.

A lot of researches have mostly used aluminium alloys are LM2, LM6, LM13 \& LM25 and other variety of series Al-1100, 2011, 2014, 2024, 2124, 6061, 7075 on two body (high stress) abrasive wear. Excluding these, within the series of aluminium alloys restricted work has been done on two body (high stress) abrasive wear [37]. During this context Al-Si alloys form a noteworthy series of the alloy system. Their composites containing hard particles are receiving importance. These materials have properties like high specific strength, high specific stiffness, better wear and seizure resistance as well as improved high temperature performance [38].

Abrasive wear is plowing of localized surface contacts by a harder material [39]. Abrasive wear mainly happens in non- metallic and metallic particles but abrasive wear mostly affected on non-metallic particles. Abrasive wear is divided into three types namely low stress (three body), high stress (two body) and gouging. Low stress abrasion has light rubbing activity of abrasive particles along with the metal surface which are the reasons of scratches and there is no work hardening. High stress abrasion is due to high stress which results in additional work hardening. Various examples of abrasion caused are in, pivots, gears, cams and rolling-contact bearings. Gouging abrasion occurs due to high stress that creates gouges or grooves on the affected surface. Some examples where it may be seen are parts of impact hammers in pulverisers, crusher liners etc.

The objective of this study was to investigate the two body abrasive wear behavior of an Al-Si alloy (BS:LM2) and its composite reinforced with $10 \& 15 \mathrm{wt} \% \mathrm{SiC}$ particles under the influence of varying applied loads and abrading distance.

\section{EXPERIMENTAL}

\section{A. Material Preparation}

Al-Si based matrix alloy and composite were prepared by liquid metallurgy route using graphite crucibles for melting. The composites were fabricated by incorporating $10 \mathrm{wt} \%$ and $15 \mathrm{wt} \%$ of $50-100 \mu \mathrm{m}$ Silicon Carbide particles on the vortex of the melt of the matrix alloy. The $\mathrm{SiC}$ particles were preheated in ambient air at $600^{\circ} \mathrm{C}$ for 2 hours prior to in the alloy melt. Mechanical stirrer rotating at a speed of $600 \mathrm{rpm}$ was used for creating the Vortex. $\mathrm{SiC}$ particles were dispersed in the melt at $800^{\circ} \mathrm{C}$ while the pouring temperature was $850^{\circ} \mathrm{C}$. Cast iron moulds were used for the solidifying of the alloy and composites. The moulds were also preheated to around $200^{\circ} \mathrm{C}$ before pouring the melts. All the castings were made in the form of finger (Length: $170 \mathrm{~mm}$, diameter: 16 $\mathrm{mm}$ ). Table 1 shows the chemical compositions of the sample materials. 


\section{B. Microstructural Examination}

Microstructural studies were carried out on $15 \mathrm{~mm}$ thick \& $10 \mathrm{~mm}$ diameter of samples. The samples were polished metallographically and etched suitably. Keller's reagent was used for etching the samples of the aluminium (matrix) alloy and composite. Microstructural characterization of the samples was conducted on using scanning electron microscopy.

\section{Measurement of Physical and Mechanical Property}

Hardness measurements were performed on metallographically polished samples using a Vickers hardness tester. The applied load in this case was 294 N. Density of the samples was determined by water displacement technique. For weighing the samples a Mettler microbalance with a precision level of $0.01 \mathrm{mg}$ was used in water and air. An average of five observation has been taken Tension test were conducted on $10 \mathrm{~mm}$ diameter, $50 \mathrm{~mm}$ G.L. specimens as per IS 1608. The tests were performed at room temperature using Instron make computerized tension testing machine. The strain rate or cross head speed used was $0.5 \mathrm{~mm} / \mathrm{min}$.

TABLE I Chemical Composition of the Test Materials

\begin{tabular}{|c|c|c|c|c|c|c|c|c|}
\hline \multirow{2}{*}{ Elements } & \multicolumn{7}{|c|}{ Elements, wt\% } \\
\cline { 2 - 10 } & $\mathrm{Si}$ & $\mathrm{Mn}$ & $\mathrm{Mg}$ & $\mathrm{Cu}$ & $\mathrm{Fe}$ & $\mathrm{Ni}$ & $\mathrm{Al}$ & $\mathrm{SiC}$ \\
\hline Al-Si Alloy & 10.29 & 0.12 & 0.47 & 1.98 & 0.75 & 0.80 & Balance & - \\
\hline Alloy + 10wt\% SiC Composite & 10.29 & 0.12 & 0.47 & 1.98 & 0.75 & 0.80 & Balance & 10 \\
\hline Alloy + 15wt\% SiC Composite & 10.29 & 0.12 & 0.47 & 1.98 & 0.75 & 0.80 & Balance & 15 \\
\hline
\end{tabular}

\section{Abrasive Wear Test}

High-stress abrasive wear tests will be conducted on $30 \mathrm{~mm}$ long and $10 \mathrm{~mm}$ diameter cylindrical samples using a pin on-disc apparatus. Diagrammatic representations of the wear test apparatus and the test configuration are shown in fig. a \& b, respectively. A polishing/emery paper having $\mathrm{SiC}$ abrasive particles $(18 \mu \mathrm{m})$ firmly bonded on a strong paper base will be used as abrasive medium in this study. The abrasive medium will be firmly put in position on the disc of the machine. The sample will be held against the rotating abrasive medium with the help of a specimen holder. Load on the sample applied through a cantilever mechanism with the assistance of dead weights. The traversal distance, track radius load and rotational speed of the disc was varied according to our need. The applied loads in this case were $1,3,5 \& 7 \mathrm{~N}$ while the track diameters adopted were $8 \mathrm{~cm}$ which enabled the rotational speeds of 300 to attain linear sliding velocities of $1.26 \mathrm{~m} / \mathrm{s}$. The specimens were tested for $1.20,2.40,4$ and 5.20 minutes to cover the distance 100, 200,300 and $400 \mathrm{~m}$ respectively. The samples polished metallographically, cleaned with acetone and weighed using the previously mentioned microbalance prior to testing. The tested samples were once again cleaned with acetone and weight loss taken at continuous interval. Friction force was measured using a load cell/force transducer placed to make contact with the rear end of the lever arm during the tests; the other end of the lever will be connected with the sample in the holder. The friction force was examine on a digital meter fixed with the controller and display unit of the test set up connected with the load cell. The measured friction force will be then converted into friction coefficient. Temperature at a distance of $1.5 \mathrm{~mm}$ from the contacting surface of the specimen was also monitored during the tests by inserting a chromel-alumel thermocouple in a $1.5 \mathrm{~mm}$ diameter hole made therein. An average of three observations will be considered in this study.
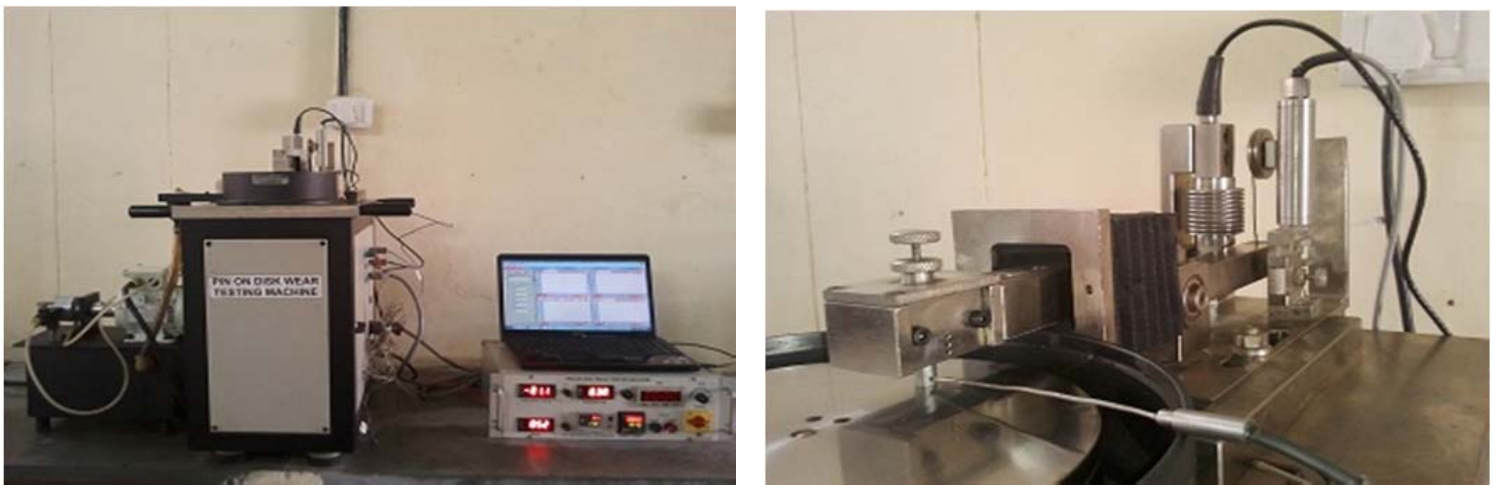

Fig. 1. (a) Schematic diagram of the wear testing machine (b) Magnified view of Pin-Disc Test Assembly 


\section{RESULTS}

\section{A. Microstructure}

Microstructure of matrix Alloy shows aluminium dendrites and eutectic silicon solidifying in interdendretic region and around dendrites. Micrograph of $10 \% \mathrm{SiC}$ reinforced composite shows secondary aluminium dendrites eutectic silicon in the dendretic spacing and around the dendrites and distribution of $\mathrm{SiC}$ particles in the matrix. Micrograph of $15 \% \mathrm{SiC}$ reinforced composite shows interphase of $\mathrm{SiC}$ particle and aluminium silicon alloy matrix and segregation of eutectic silicon at the interphase. The $\mathrm{SiC}$ particles are noted to be uniformly distributed within the metallic matrix and these particles are trapped within the primary aluminium dendrites rather than of interdendretic region (figure 2).

\section{B. Hardness, Density and Tensile Strength}

Table 2 represents various properties of the specimens. The composites attain higher density and hardness than the matrix alloy and both the properties are increased with increase in $\mathrm{SiC}$ content. Further, incorporation of $\mathrm{SiC}$ particles in to the matrix alloy reduces their tensile strength and the rate of decrement increases with the increase in $\mathrm{SiC}$ content.

Table II Hardness and Density of Specimen

\begin{tabular}{|l|c|c|c|}
\hline \multicolumn{1}{|c|}{ Type } & Vickers Hardness (HV) & Density g/cm & Tensile Strength (MPa) \\
\hline Matrix Alloy & 92.3 & 2.64 & 152.1 \\
\hline Matrix Alloy + 10\% SiC Composite & 98.7 & 2.78 & 124.3 \\
\hline Matrix Alloy + 15\% SiC Composite & 107.1 & 2.79 & 119.7 \\
\hline
\end{tabular}

C. Wear Behaviour

1) Wear rate: Wear rate of the specimens has been plotted as a function of abrading distance at an applied load of $1 \mathrm{~N}$ and $7 \mathrm{~N}$ for different test materials are shown in figure 3 . The wear rate decreases with the increase in abrading distance for all the test materials and at all the loading conditions. It is observed that wear rate is maximum for the matrix alloy and addition of $\mathrm{SiC}$ into the matrix alloy reduces their rate also the rate of reduction of wear rate increases with the increase $\mathrm{SiC}$ content. Abrasive wear loss of the test materials plotted as a function of applied load at an abrading distance of 400 metres is shown in figure 4 . Moreover the tendency of wear increases with the increase in applied load of all the test materials however the slope of increment is maximum for the base alloy and maximum for the $15 \% \mathrm{SiC}$ reinforced composite while $10 \% \mathrm{SiC}$ reinforced composite revealed immediate response.

2) Frictional Heating: Temperature near the contact surface for matrix Alloy, $10 \% \mathrm{SiC}$ and $15 \% \mathrm{SiC}$ composite at an applied load of $1 \mathrm{~N}$ and $7 \mathrm{~N}$ plotted as a function of abrading distance is shown in figure 5 . The temperature rises linearly with the test duration and the maximum frictional heating is attained by $15 \% \mathrm{SiC}$ Composite followed by $10 \% \mathrm{SiC}$ and matrix Alloy. As far as the effect of load on the frictional heating is concerned, the temperature increases with the increase in applied load irrespective of the test material however the severity of increase is maximum for $15 \% \mathrm{SiC}$ composite and minimum for the matrix Alloy (Figure 6).

3) Friction coefficient: Figure 7 represents friction coefficient for matrix Alloy, $10 \% \mathrm{SiC}$ and $15 \% \mathrm{SiC}$ composite as function of abrading distance at an applied load of $1 \mathrm{~N}$ and $7 \mathrm{~N}$. The friction coefficient decreases with the increase in test duration for all the test material and it is observed that the friction coefficient is maximum for matrix Alloy followed by $10 \% \mathrm{SiC}$ and $15 \% \mathrm{SiC}$ composite, however an increase in load increases the friction coefficient and the maximum increase is obtained for matrix alloy and minimum for $15 \%$ $\mathrm{SiC}$ composite while $10 \% \mathrm{SiC}$ composite revealed intermediate behaviour (Figure 8).
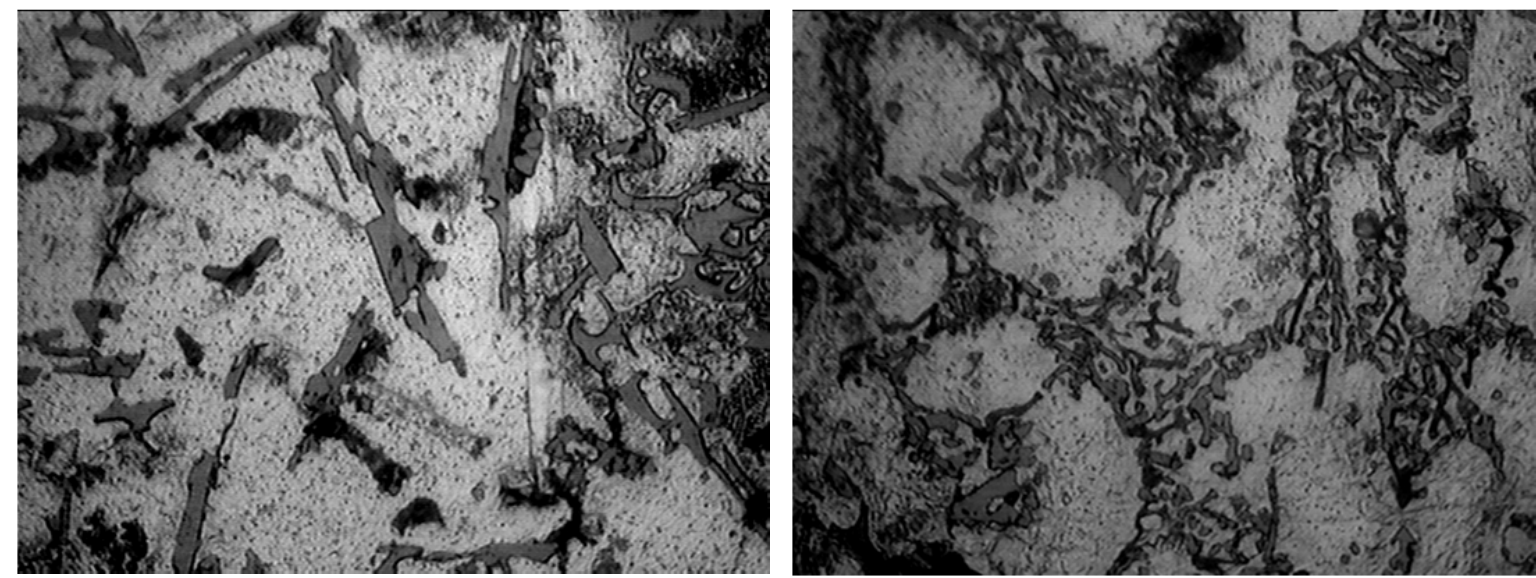
(a)

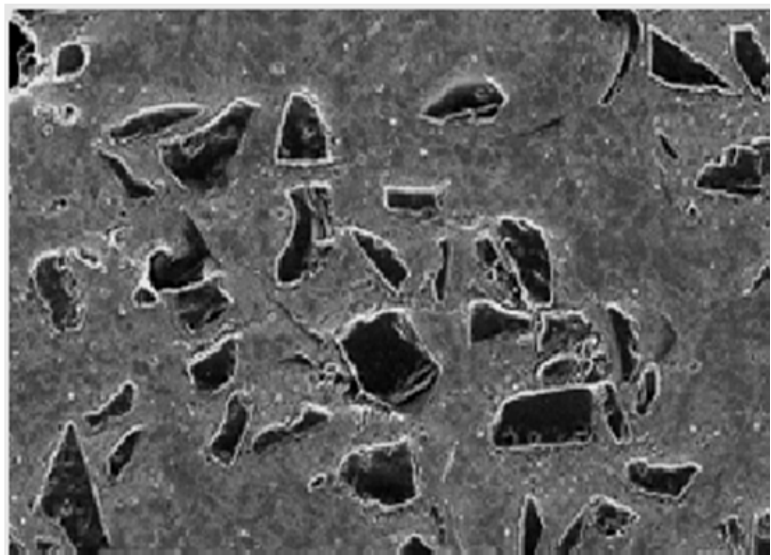

(c) (b)

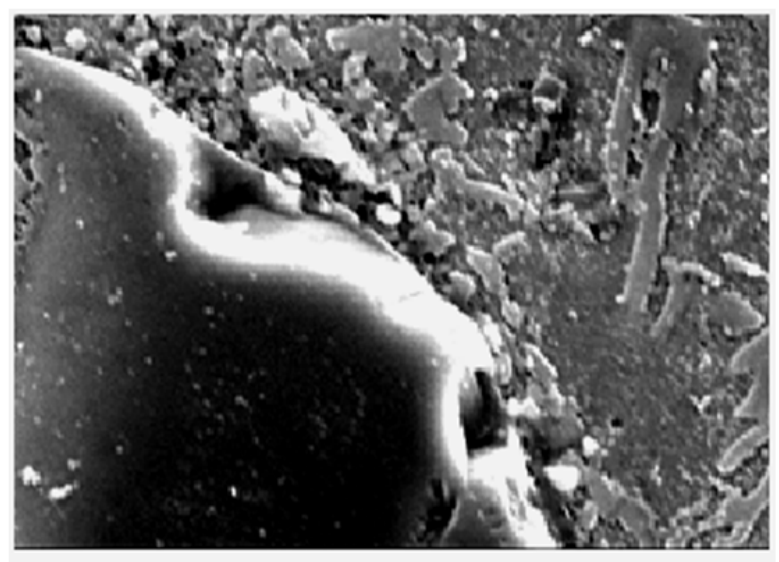

(d)

Fig. 2. Microstructure of Matrix Alloy (a), 10wt $\%$ SiC Composite (b), $15 \mathrm{wt} \% \mathrm{SiC}$ composite(c) and higher magnification micrograph of 15 $\mathrm{wt} \% \mathrm{SiC}$ composite showing interphase of matrix alloy and $\mathrm{SiC}$ particle (d)

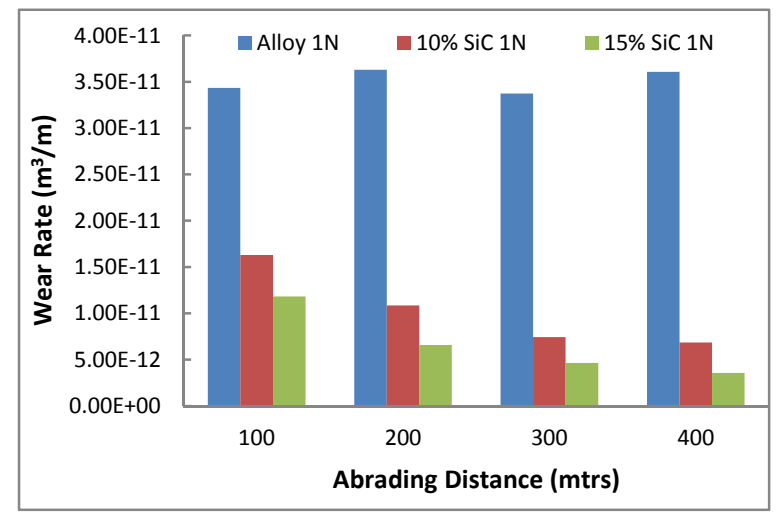

(a)

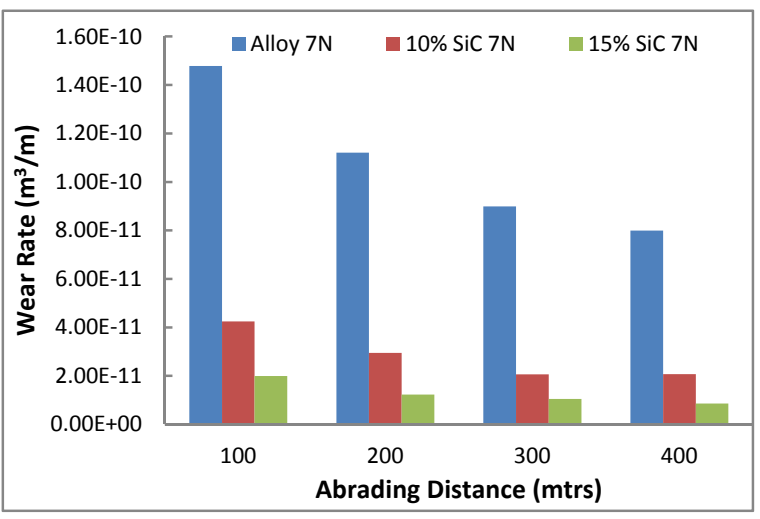

(b)

Fig. 3. Abrasive wear loss of the test materials plotted as a function of abrading distance at an applied load of $1 \mathrm{~N}$ (a) and $7 \mathrm{~N}$ (b).

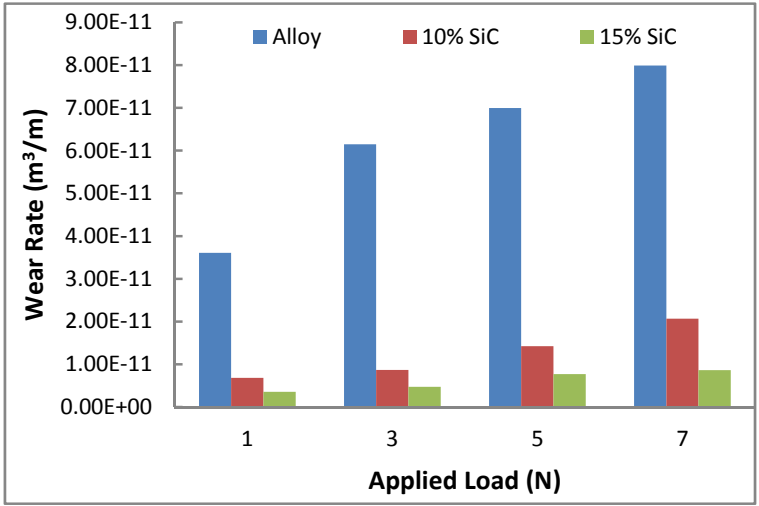

Fig. 4. Abrasive wear loss of the test materials plotted as a function of applied load at an abrading distance of 400 metres. 


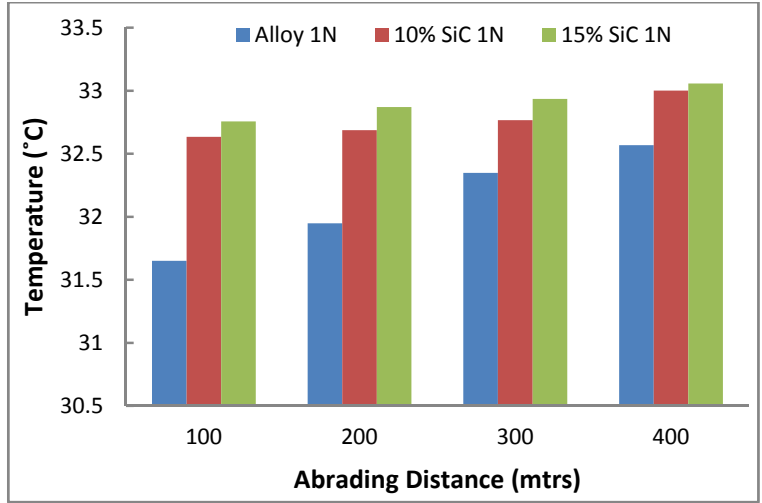

(a)

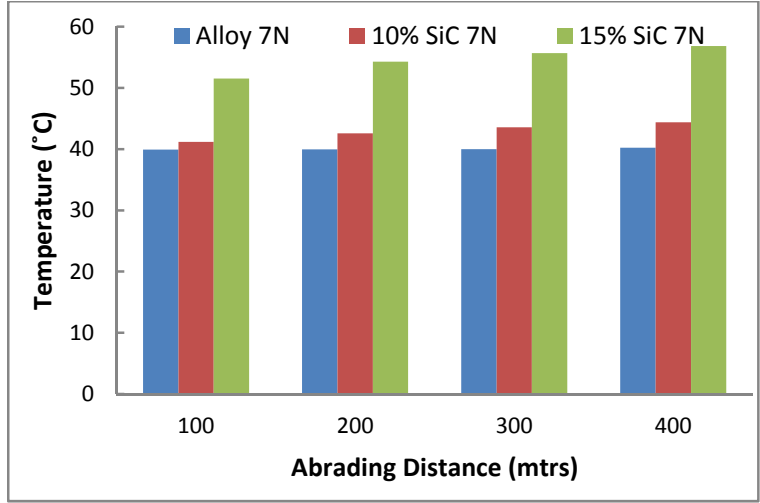

(b)

Fig. 5. Frictional Heating of the samples plotted as a function of Abrading Distance at the applied load of $1 \mathrm{~N}$ (a) and $7 \mathrm{~N}$ (b)

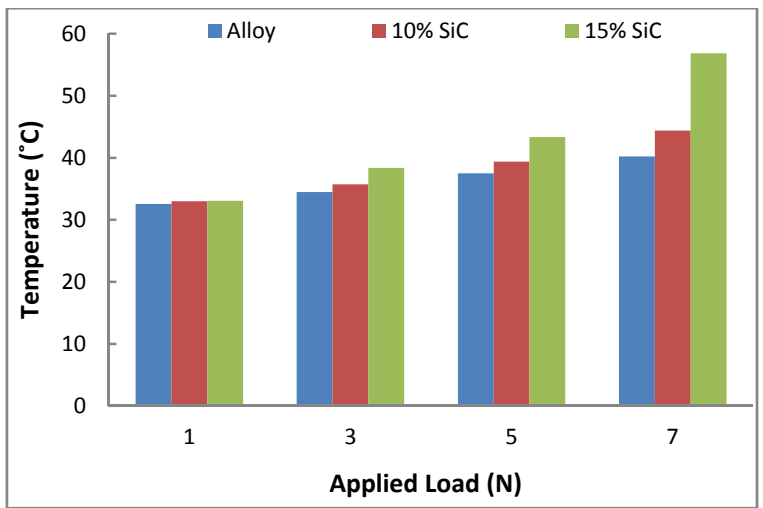

Fig. 6. Frictional Heating of the samples plotted as a function of applied load at an abrading distance of 400 metres

\section{DISCUSSION}

From Microstructural point of view, the Al-Si alloy contains plate shaped eutectic silicon and the other intermetallic phases. As the ambient temperature solid solubility of Silicon in Aluminium is negligible the eutectic structure contains Aluminium and Silicon. SiC reinforced composite shows secondary Al dendrites eutectic si in the dendretic spacing and around the dendrites. The $\mathrm{SiC}$ particles are noted to be uniformly distributed within the metallic matrix and these particles are trapped within the primary aluminium dendrites rather than of interdendritic region.

The matrix alloys attains lower hardness and the hardness increases with increase in $\mathrm{SiC}$ content. This is due to the fact that the volume fraction of relatively higher harder phase increases in the matrix alloy. As far as tensile strength is concerned, the matrix alloy attains higher tensile strength and addition of $\mathrm{SiC}$ particles in the matrix slightly reduces the tensile strength this is because of the fact that $\mathrm{SiC}$ particles are generally ceramic in nature and the bonding between $\mathrm{Si}$ and $\mathrm{Al}$ is very week like vanderwall bonding. At the temperature of processing of composite materials $\mathrm{Al}$ and $\mathrm{SiC}$ does not react together and thus there is no possibility of forming interface products. During tensile stress there is decohesion at particle matrix interface and which results into void formation. The probability of void formation is high in the case of coarse particles $(50-100 \mu \mathrm{m})$ in Aluminium matrix thereby decreasing the tensile strength in case of composite materials. 


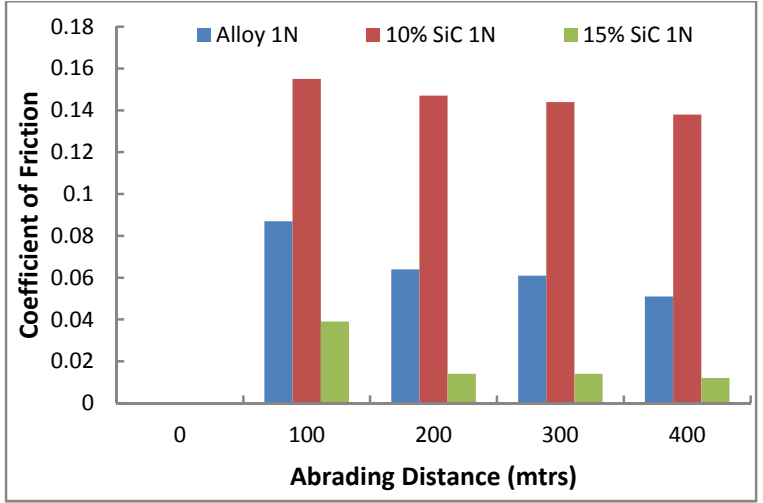

(a)

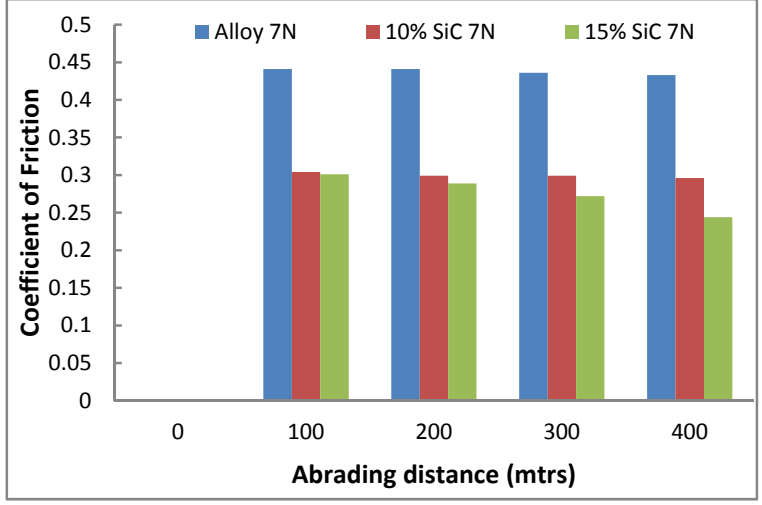

(b)

Fig. 7. Friction coefficient of the samples plotted as a function of Abrading Distance at the applied load of $1 \mathrm{~N}$ (a) and $7 \mathrm{~N}$ (b).

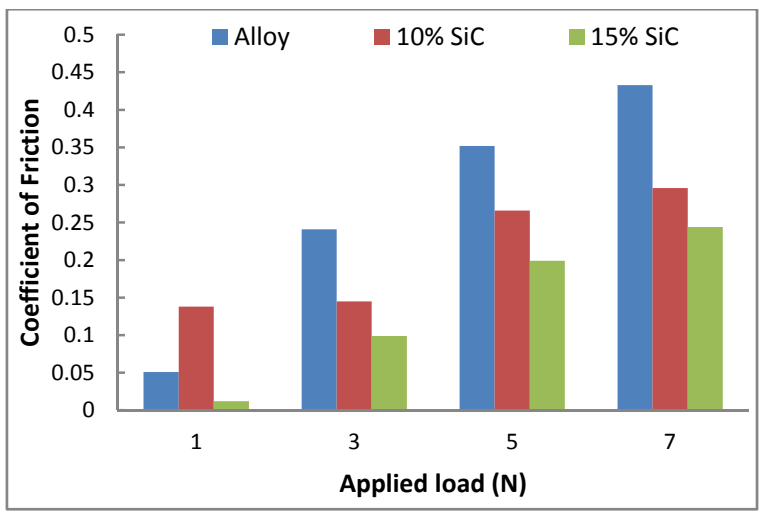

Fig. 8. Friction coefficient of the samples plotted as a function of applied load at an abrading distance of 400 metres

The abrasive wear is associated with the penetration of the hard rigid abrasives and subsequent scratching of the specimen surface by the penetrated abrasives. The scratching of the abrasives leads to the continuous groove marks. The depth of penetration (i.e., the width and the depth grooves) depends on applied load and relative hardness of the abrasive with respect to the specimen surface hardness. As the hardness of the composite is higher than that of the alloy, it is expected that the depth of penetration of the abrasive in the composite surface is less as compared to the alloy. Additionally, SiC particles on the composite surface act as protrusions, which carry the major portion of the applied load and this helps in protecting the matrix alloy from severe contact of abrasives. As a result, relatively less material is removed from the composite surface as compared to the alloy due to cutting or plowing action. The wear resistance of the composite also depends to a significant extent on the interfacial bonding between $\mathrm{SiC}$ and the matrix alloy and the fracturing tendency of SiC particles. It is reported by several earlier studies that the composite is superior to the alloy (as far as wear resistance is concerned) provided the bonding is strong enough to hold the particle on the wear surface intact and the hard ceramic particles are not fractured or fragmented. Important events during abrasion of the samples as far as the abrasive particles are concerned include capping, clogging, shelling and attrition. Especially attrition becomes quite effective in reducing the abrasion rate when the same abrasive comes in contact with the specimen surface in a cyclic manner. Interaction with relatively sharper abrasive particles in the starting of the tests could lead to higher rate of increase in wear rate and temperature. As the test duration increases to sufficiently dull the abrasive particles, the rate of increase is reduced.

Highest friction coefficient and frictional heating of the most ductile matrix alloy could be due to a larger depth of penetration of the abrasive particles on the samples. A reduction in the severity of penetration due to the hard $\mathrm{SiC}$ reinforcement in the alloy matrix caused the friction coefficient and frictional heating of the composite to decrease on the contrary to that of the matrix alloy. Higher wear rate, friction coefficient and frictional heating with increasing load may be attributed to a larger depth of penetration by the abrasive particles on the specimen surface. The friction coefficient in turn appears to have predominantly been controlled by the factors like capping, clogging, shelling and attrition of the abrasive particles leading to a decrease in their cutting efficiency/depth of penetration and hence a reduction in friction coefficient of the samples with test duration. 


\section{CONCLUSION}

Microstructure of matrix Alloy shows aluminium dendrites and eutectic silicon solidifying in interdendretic region and around dendrites. The composite under shows similar behaviour to those of the base alloy except the additional presence of the reinforced $\mathrm{SiC}$ particles.

Incorporation of $\mathrm{SiC}$ particles reduces the density but increases the hardness of the base alloy.

The wear rate decreases with the increase in abrading distance for all the test materials and at all the loading conditions. Dispersion of $\mathrm{SiC}$ particles reduces the wear rate. Increment in the applied load increases the wear for all the test material however the slope of increase is maximum for the base alloy followed by $5 \%$ and $10 \%$ $\mathrm{SiC}$.

The temperature rises linearly with the test duration and $10 \% \mathrm{SiC}$ reinforced composite attained maximum frictional heating followed by $5 \% \mathrm{SiC}$ reinforced composite and Matrix alloy. Increase in applied load increases the temperature irrespective of the test material however the severity of increase is maximum for $10 \% \mathrm{SiC}$ composite and minimum for the Matrix Alloy.

The friction coefficient decreases with the increase in test duration for all the test material and maximum friction coefficient is observed for Matrix Alloy followed by $5 \% \mathrm{SiC}$ and $10 \% \mathrm{SiC}$ reinforced composite, increases in load increases the friction coefficient and the maximum increase is obtained for matrix Alloy and minimum for $10 \% \mathrm{SiC}$ reinforced composite while $5 \% \mathrm{SiC}$ reinforced composite revealed intermediate behaviour.

\section{REFERENCES}

[1] C. Lane, In Machining of Composite Materials, T. S. Srivatsan and D. M. Bowden, eds., ASM International, Materials Park, OH. pp. 3-15, 1992.

[2] W. S. Lau, T. M. Yue, C. Y. Jiang, and S. Q. Wu, In Machining of Composite Materials, T.S. Srivatsan and D. M. Bowden, eds., ASM International, Materials Park, OH, pp. 29-34, 1992.

[3] L. M. Orsborn and G. R. Shook, In Machining of Composite Materials, T.S. Srivatsan and D.M. Bowden, eds., ASM International, Materials Park, OH, pp. 57-61, 1992.

[4] M. Finn and G. Hughes Institute of Advanced Manufacturing Science, Cincinnati, Ohio. Report No. APQ-142, 1991.

[5] J. Jawaid, S. Barnes and S. R. Ghadimzadeh, In Machining of Composite Materials, T. S. Srivatsan and D. M. Bowden, eds., ASM International Materials Park, OH, pp. 35-47, 1992.

[6] S.Das, A. K. Jha, B. K. Prasad, O. P. Modi and A. H. Yegneswaran, "Microstructure and wear of Aluminium alloy matrix composites," Proceedings of the XI NCIT, 1995, pp. 22-25.

[7] B. K. Prasad, K.Venkateswarlu, S. Das, A. K. Jha and R. Dasgupta, "Influence of SiC reinforcement on the abrasive wear response of an Al-Cu alloy under conditions of varying abrasive size and applied load," Journal of Materials Science Letters, 16, pp. 1113-1115 1997.

[8] S. Al-Rubaie Kassim, N. Yoshimura Humberto and Jose Daniel Biasoli de Mello, "Two-body abrasive wear of Al-SiC composites," Wear, 233-235, pp. 444-454, 1999.

[9] S. Das, S. Gupta, D. P. Mondal, B. K. Prasad, "Influence of load and abrasive size on the abrasive wear of Al-SiC composites," Aluminium Transactions volume, 2(1), pp. 27-36, 2000.

[10] S. Das, D.P. Mondal, and G. Dixit, "Correlation of Abrasive Wear with Microstructure and Mechanical Properties of Pressure DieCast Aluminum Hard-Particle Composite," Metallurgical and Materials Transactions A, 32, pp. 633-642 2001.

[11] E. Candan, H. Ahlatci and H. C. Imenoglu, "Abrasive wear behaviour of Al-SiC composites produced by pressure infiltration technique," Wear, 247, pp. 133-138,2001.

[12] Y. Sahin, "Wear behaviour of aluminium alloy and its composites reinforced by SiC particles using statistical analysis," Materials and Design, 24, pp. 95-103, 2003.

[13] S. Sawla and S. Das, "Combined effect of reinforcement and heat treatment on the two body abrasive wear of aluminum alloy and aluminum particle composite," Wear, 257, pp. 555-561, 2004.

[14] Hayrettin Ahlatci, Ercan Candan, and Hüseyin Ç’1meno glu, "Abrasive wear behavior and mechanical properties of $\mathrm{Al}-\mathrm{Si} / \mathrm{SiC}$ composites," Wear, 257, pp. 625-632. 2004.

[15] D.P. Mondal and S. Das, "High stress abrasive wear behaviour of aluminium hard particle composites: Effect of experimental parameters, particle size and volume fraction," Tribology International, 39(6), pp. 470-478, 2006.

[16] M. Murato glu and M. Aksoy, "Abrasive wear of 2124Al-SiC composites in the temperature range 20- $200{ }^{\circ}$," Journal of Materials Processing Technology, 174, pp. 272-276, 2006.

[17] Y. Sahin and K. Ozdin, "A model for the abrasive wear behavior of aluminium based composites," Materials and Design, 29, pp. 728$733,2008$.

[18] S. Das, D.P. Mondal, S. Sawla and N. Ramakrishnan, "Synergic effect of reinforcement and heat treatment on the two body abrasive wear of an Al-Si alloy under varying loads and abrasive sizes," Wear, 264, pp. 47-59 2008.

[19] Yusuf Sahin, "Abrasive wear behaviour of SiC/2014 aluminium composite" Tribology International, 43, pp. 939-943,2010.

[20] S. Kumar and V. Balasubramanian, "Effect of reinforcement size and volume fraction on the abrasive wear behaviourof AA7075Al/SiCp P/M composites-A statistical analysis," Tribology International, 43 (1-2), pp. 414-422, 2010.

[21] Y. Sahin and V. Kilicli, "Abrasive wear behaviour of SiCp/Al alloy composite in comparison with ausferritic ductile iron," Wear, 271, pp. 2766-2774, 2011.

[22] M. K. Surappa, S.V. Prasad and P.K. Rohatgi, "Wear and abrasion of cast Al-Alumina particle composites," Wear, 77, pp. 295-302, 1982.

[23] D.P. Mondal, S. Das, A.K. Jha and A.H. Yegneswaran, "Abrasive wear of Al alloy-Al2O3 particle composite: a study on the combined effect of load and size of abrasive," Wear, 223, pp. 131-138, 1998.

[24] O.P. Modi, "Two-body abrasion of a cast Al-Cu (2014 Al) alloy-Al2O3 particle composite: influence of heat treatment and abrasion test parameters," Wear, 248, pp. 100-111, 2001.

[25] M. Kok, "Abrasive wear of Al2O3 particle reinforced 2024 aluminium alloy composites fabricated by vortex method," Composites: Part A, 37, pp. 457-464, 2006.

[26] Sanjeev Das, Siddhartha Das and Karabi Das, "Abrasive wear of zircon sand and alumina reinforced Al-4.5 wt\%Cu alloy matrix composites - A comparative study," Composites Science and Technology, 67, pp. 746-751, 2007. 
[27] M. Kok and K. Ozdin, "Wear resistance of aluminium alloy and its composites reinforced by $\mathrm{Al}_{2} \mathrm{O}_{3}$ particles," Journal of Materials Processing Technology, 183, pp.301-309, 2007.

[28] S. Das, "The influence of matrix microstructure and particle reinforcement on the two-body abrasive wear of an Al-Si alloy," Journal of Materials Science Letters, 16, pp. 1757-1760, 1997.

[29] Ali Mazahery and Mohsen Ostad Shabani, "Study on microstructure and abrasive wear behavior of sintered Al matrix composites," Ceramics International, 38, pp. 4263-4269, 2012.

[30] M. Singh, A.K. Jha, S. Das and A.H. Yegneswaran, "Preparation and Properties of Cast Aluminium alloy- Granite Particle Composite," Journal of Material Science, 35, pp. 4421-4426, 2000

[31] M. Singh, D.P. Mondal, R. Dasgupta and A.K. Jha, "Combined effect of load, abrasive size and sliding distance on the high stress abrasive wear of an aluminium composite," Aluminium Transactions, 3(1), pp. 7-15, 2000.

[32] M. Singh, D.P. Mondal, A.K. Jha, S. Das and A.H. Yegneswaran, "Preparation and Properties of Cast Aluminium alloy- Sillimanite Particle Composite," Composites: Part A, 32, pp. 787-795, 2001.

[33] M. Singh, D.P. Mondal, O.P. Modi and A.K. Jha, "Two-body abrasive wear behaviour of aluminium alloy-sillimanite particle reinforced composite," Wear, 253, pp. 357-368, 2002.

[34] K. Anand and Kishor, "On the wear of aluminium-corundum composites," Wear, 85(2), pp. 163-169, 1983.

[35] O. Vingsbo in: Proceedings of the Conference on Wear of Materials," ASME, New York, USA: 620, 1979.

[36] M. Singh, O.P. Modi, R. Dasgupta and A.K. Jha, "High stress abrasive wear behaviour of aluminium alloy-granite particle composite," Wear, 233-235, pp. 455-461, 1999.

[37] Raj Kumar Singh, Amit Telang and S. Das, "High stress abrasive wear behaviour of aluminium alloy and composite: a review," ARPN Journal of Engineering and Applied Sciences, 10(8), pp. 8025-8037, 2015.

[38] Gajendra Dixit and Mohammad Mohsin Khan, "Sliding wear response of an aluminium metal matrix composite: effect of solid lubricant particle size," Jordan Journal of Mechanical and Industrial Engineering, 8(6), pp. 351-358, 2014.

[39] ASM Handbook, Friction, Lubrication, and Wear Technology, U.S.A. 18, pp. 713, 1992.

\section{AUTHOR PROFILE}

Raj Kumar Singh, Research Scholar, Dept. of Mechanical Engg, MANIT, Bhopal, India. He has obtained his Bachelor of Engineering degree in Mechanical Engineering from RGPV Bhopal, India and Master of Technology in Engineering Materials from MANIT, Bhopal, India. His research interests are Metal Matrix Composites and Tribology.

Mohammad Mohsin Khan, Research Scholar, Dept. of Mechanical Engg, MANIT, Bhopal, India. He has obtained his Bachelor of Engineering degree in Mechanical Engineering from RGPV Bhopal, India and Master of Technology in Engineering Materials from MANIT, Bhopal, India. His research interests are Synthesis \& characterization of Composite materials and Tribology.

Amit Telang is currently working as an Assistant Professor, Dept. of Mechanical Engg, MANIT, Bhopal, India. He has received his Bachelor of Engineering degree in Mechanical Engineering from MACT, Barkatullah University Bhopal, India and Master of Technology in Industrial Design from MACT, Barkatullah University, Bhopal, India. His research interests are in Engineering Materials, Composite Materials and Design. 